UPGRADE is the European Journal for the Informatics Professional, published bimonthly at $<$ <ttp://www.upgrade-cepis.org/>

\section{Publisher}

UPGRADE is published on behalf of CEPIS (Council of European Professional Informatics Societies, $<$ http://www.cepis.org/>) by NOVÁTICA $<$ http://www.aties/novatical>, journal of the Spanish CEPIS society ATI (Asociación de Técnicos de Informática $<$ http://www.ati.es/>)

UPGRADE is also published in Spanish (full issue printed, some articles online) by NOVÁTICA, and in Italian (abstracts and some articles online) by the Italian CEPIS society ALSI

$<h t t p: / / w w w . a l s i . i t>$ and the Italian IT portal Tecnoteca $<$ http://www.tecnoteca.it/>.

UPGRADE was created in October 2000 by CEPIS and was first published by NOVÁTICA and INFORMATIK/INFORMATIQUE, bimonthly journal of SVI/FSI (Swiss Federation of Professional Informatics Societies, <http://www.svifsi.ch/>).

\section{Editorial Team}

Chief Editor: Rafael Fernández Calvo, Spain <rfcalvo@ati.es> Assistant Editors:

- François Louis Nicolet, Switzerland, <nicolet@acm.org>

- Roberto Carniel, Italy, <carniel@dgt.uniud.it>

\section{Editorial Board}

Prof. Wolffried Stucky, CEPIS President

Fernando Piera Gómez and

Rafael Fernández Calvo, ATI (Spain)

François Louis Nicolet, SI (Switzerland)

Roberto Carniel, ALSI - Tecnoteca (Italy)

English Editors: Mike Andersson, Richard Butchart, David Cash, Arthur Cook, Tracey Darch, Laura Davies, Nick Dunn, Rodney Fennemore, Hilary Green, Roger Harris, Michael Hird Jim Holder, Alasdair MacLeod, Pat Moody, Adam David Moss Phil Parkin, Brian Robson.

Cover page and illustrations designed by Antonio Crespo Foix, @ ATI 2003

Layout: Pascale Schürmann

E-mail addresses for editorial correspondence: <nicolet@acm.org> and <rfcalvo@ati.es>

E-mail address for advertising correspondence: <novatica@ati.es>

Upgrade Newslist available at

<http://www.upgrade-cepis.org/pages/editinfo.htm|\#newslist> Copyright

(c) NOVA்TICA 2003. All rights reserved. Abstracting is permitted with credit to the source. For copying, reprint, or republication permission, write to the editors.

The opinions expressed by the authors are their exclusive responsibility.

ISSN 1684-5285

\section{UPGRADE \\ The European Journal for the Informatics Professional http://www.upgrade-cepis.org \\ Vol. IV, No. 3, June 2003}

2 Editorial. Reassignment of Editorial Functions in Upgrade - Prof. Wolffried Stucky (President of CEPIS)

\section{Open Knowledge}

\section{Guest Editors: Philippe Aigrain and Jesús M. González-Barahona}

\section{Joint issue with NOVÁTICA}

3 Presentation. Ownership and Terms of Use for Intangibles. Land Grab or Commons? - Philippe Aigrain and Jesús M. González-Barahona

The guest editors present the issue, where they have offered the floor to a very diverse set of contributors, united by the effort to understand and promote information-based commons and convinced that a prosperous and more human economy can develop on its basis. They also provide a list of useful references for those interested in knowing more about this subject.

6 The Political Economy of Commons - Yochai Benkler

In this article the author defines the structure of the information commons, its sustainability, and its importance for democracy and for individual freedom.

10 The Rediscovery of the Commons - David Bollier

The author explains how a large part of the current information society is already a commons, which plays a vital role in the economical and cultural production.

13 Language in the Digital Media: A Political Challenge - José-Antonio Millán

The author analyses the situation of most languages in the digital domain, and how the promotion of a publicly available infrastructure of language-related software would serve to the societies using those languages.

16 A Note on Software Patents - Pierre Haren A set of brief notes with his opinions on software patents is offered by the author.

17 On the Patentability of Inventions Involving Computer Programmes - Alberto Bercovitz Rodríguez-Cano

This article reproduces in substance the author's address to the European Parliament during the hearing held on November 2002 on the Proposal for a European Directive on the Patentability of Computer Implemented Inventions.

21 Legal Tools to Protect Software: Choosing the Right One - Roberto Di Cosmo This is an article in which the author analyses the different legal tools aimed at dealing with software protection.

24 Petition to the European Parliament on the Proposal for a Directive on the Patentability of Computer-implemented Inventions - Several European computer scientists and engineers

Petition written by several prestigious European computer scientists and engineers, related to the proposed Directive on software patents currently being discussed at the European Parliament.

26 The Right to Read - Richard Stallman

This is a short fiction story, 45 years ahead, in which the author, by extrapolating from some current trends, shows a future where access to information is tightly controlled, and the so called "trusted computing" is fully deployed.

29 Please, Pirate My Songs! - Ignacio Escolar

A musician describes the current situation of the music industry from his specific point of view.

31 The EUCD and the DMCA in 2003: How Legal Protection for Technological Measures is shaping Consumers' and Copyright Owners' Digital Rights - Gwen Hinze

This paper reviews the United States' experience under the Digital Millennium Copyright Act and contends that Member States' implementation legislation should include exceptions permitting circumvention for lawful uses and socially valuable activities. It also analyses a new technological protection regime contemplated by the 2003 draft of the European Union.

35 'Trusted Computing' and Competition Policy - Issues for Computing Professionals - Ross Anderson

In this paper, the author gives an outline of Trusted Computig and sketches some of the possible effects on the computing business and the people who work in it.

42 Software Patentability and CEPIS - Upgrade Editor's Contribution

The Editor of Upgrade introduces and publishes the positions on software patents put forward by two CEPIS member societies - GI, Germany, and ATI, Spain.
Coming issue:

"Software Engineering: The State of an Art" 


\title{
The Political Economy of Commons
}

\author{
Yochai Benkler
}

(C) 2003 by Yochai Benkler. This Work is licensed under the Public Library of

Science Open Access License, and the Creative Commons Attribution License.

The paper defines the institutional and normative characteristic of commons, and explains why they are sustainable under many circumstances. It explains why maintaining a core common infrastructure in resources necessary for information production and exchange throughout the information environment is important both for democracy and for individual freedom. It concludes by outlining a series of practical policy actions necessary to build such a core common infrastructure.

Keywords: autonomy, commons, commons - economic sustainability, commons - institutional characteristics, democracy, information policy.

\section{Why Commons?}

Commons are institutional spaces, in which we can practice a particular type of freedom - freedom from the constraints we normally accept as necessary preconditions to functional markets.

- Though we often think of 'free markets' as spaces that enable free choice, in fact these are structured relationships intended to elicit a particular datum - the comparative willingness and ability of agents to pay money for resource.

- The most important constraints under-girding markets are those we usually call property. Property is a cluster of background rules that determine

- what resources each of us has when we come into relations with others

- what 'having' or 'lacking' a resource allows us to do or refuse to do in relations surrounding resources. These rules impose constraints on who can do what in the domain of actions that require access to resources that are the subjects of property law.

- While a necessary precondition for markets, property law means that choice in markets is itself not free of constraints, but is instead constrained in a particular pattern.

- Commons are institutional spaces where human agents can act free of the particular constraints required for markets.

- This does not mean that commons are anarchic spaces. Purely free action is illusory.

- It means that individuals and groups can use resources governed under different types of constraints than those imposed by property law. These constraints may be social, or physical, or regulatory. They may make individuals more or less free, in some aggregate sense, than do property rules. Whether a commons in fact enhances freedom or harms it then, depends on how the commons is structured, and on how property rights in the resource would have been structured in the absence of a commons.

\section{What are Commons?}

Commons are a particular type of institutional arrangement for governing the use and disposition of resources. Their salient characteristic, which defines them in contradistinction to property, is that no single person has exclusive control over the use and disposition of any particular resource. Instead, resources governed by commons may be used or disposed of by anyone among some (more or less well defined) number of persons, under rules that may range from 'anything goes' to quite crisply articulated formal rules that are effectively enforced.

- Commons can be divided into four types based on two parameters.

- The first parameter is whether they are open to anyone or only to a defined group. The oceans, the air, and highway systems are clear examples of open commons. Various traditional pasture arrangements or irrigation regions are nowclassic examples, described by Eleanor Ostrom, of limitedaccess commons - where access is limited only to members

Yochai Benkler is a Professor of Law at Yale Law School (USA.) Prior to joining Yale, he was a professor at New York University School of Law, where he was the Director of the Engleberg Center for Innovation Law and Policy and of the Information Law Institute. His research focuses on the effect of the interaction of law, technology and economic structures on the organization of information production and exchange, and on the distribution of control over information flows, knowledge, and culture in the digital environment. He has written in particular about the role and sustainability of non-proprietary, or commons-based approaches towards information production and exchange throughout the layers of the digital environment, and on their role in terms of democracy and individual freedom. <benklery@juris.law.nyu.edu> 
of the village or association that collectively "owns" some defined pasturelands or irrigation system. These are better thought of as common property regimes, rather than commons, because they behave as property vis-à-vis the entire world except members of the group who together holds them in common.

- The second parameter is whether a commons system is regulated or unregulated. Practically all well studied limited common property regimes are regulated by more or less elaborate rules - some formal, some social-conventional governing the use of the resources. Open commons, on the other hand, vary widely. Some commons are governed by no rule. These are called open access commons. Anyone can use resources within these types of commons at will and without payment. Air is such a resource with respect to air intake (breathing, feeding a turbine). Air is, however, a regulated commons with regard to out take. For individual human beings, breathing out is mildly regulated by social convention - you do not breath too heavily on another human being's face unless forced to. Air is a more extensively regulated commons for industrial exhalation - in the shape of pollution controls. The most successful and obvious regulated commons in contemporary landscapes are the sidewalks, streets, roads, and highways that cover our land and form the foundation of our ability to move from one place to the other. The most important resource we govern as an open commons, without which humanity could not be conceived, is all of pre-twentieth century knowledge and culture, most scientific knowledge of the first half of the twentieth century, and much of contemporary science and academic learning.

\section{Are Commons Sustainable?}

In the late 1960s Garrett Hardin coined an immensely effective trope, "the tragedy of the commons." Originally aimed to explain why private incentives would lead to firms to pollute their environment even against their own long term interest, and thereby to justify pollution controls, the trope took on a life of its own. It came to stand for a proposition that all commons are tragic, and that property rights are a necessary precondition to efficient, or even sustainable, resource management. Over the past twenty years or so, we have seen the development of a literature that challenges this now-standard understanding of commons. Most crisply this effort has come to be crystallized in the work of Eleanor Ostrom. A recent review and bibliographic essay by Hess and Ostrom provides an excellent overview of this literature. The crux of most of this work is that there are certain circumstances under which common property regimes are sustainable, and quite possibly more efficient than individual property regimes.

More generally, one can say that commons and property exist on a spectrum of institutional arrangements. Where along this spectrum a resource management system should be so as to be sustainable and efficient depends on technological characteristics of the resource and on patterns of its usage at any given historical moment. Carol Rose early identified that resources that have increasing returns to scale on the demand side, like network externalities, are particularly good candidates for commons. She used this insight to suggest why roads and canals, classic trade instrumentalities, tended to gravitate towards commons models even if they began as private property. Ellickson described a phenomenon in land, whereby the size of the group of owners - from one to many - is a function of the use of land and the likely failures that would have to be dealt with in its management. With regard to information, culture, and communications systems, I have explained how resources necessary for information production and communications systems can be managed as commons in ways that are sustainable and desirable.

Information is a public good in the strict economic sense, and is also input into its own production process. Because of these unusual characteristics, few, if any, economists would argue against the proposition that a substantial commons in information goods is not only sustainable, but indeed is necessary for efficient and innovative information production systems.

Beyond the public goods characteristics of information, the digitally networked environment is also pervaded by resources that, while not public goods in the strict economic sense, nonetheless function well on a commons model. They represent instances where sharing resources in a commons tends to reduce scarcity and perform better than property-based systems. I have written in detail about why wireless communications capacity has this characteristic and why human creativity in large scale, Internet-based collaborations like free software and other peer production enterprises similarly share this characteristic.

The core point across these different domains of resources for information production and communication is that there is some aspect of a resource - like wireless communications capacity, human creativity, distributed processing capacity, distributed storage - that make its clearance through a market particularly clunky, expensive, and inefficient. In those cases, low cost communications and cheap processors that form an integral part of information production and exchange make the conditions ripe for sustainable large-scale collaborations and a sharing of resources based on commons, rather than propertyoriented, institutional arrangements. 


\section{Why Should we Care?}

There are many reasons to care about the extent to which our information environment includes substantial commons. Most commonly spoken of today are concerns of innovation policy. As Lessig has explicated so well, commons throughout the networked environment are necessary to allow innovation to progress without the permission of incumbents who would seek to constrain the path of innovation to fit their own business plans for where technology should go.

But commons in information, culture, and knowledge are not only, or even primarily, a question of innovation. Commons are about freedom. Commons are institutional spaces in which we are free of the constraints imposed by the requirements of markets. When we speak of the information environment, of the cultural and symbolic space we occupy as individuals and citizens, diversification of the constraints under which we operate, including creating spaces relatively free of marketstructuring laws, goes to the very heart of freedom and democracy.

The commercial mass media environment has created two effects of central importance to democracy. One may be called the Berlusconi effect - the disproportionate political power that ownership over mass media outlets gives its owners or those who can pay them. The other may be called the Baywatch effect - the systematic displacement of public discourse by the distribution of commodifiable entertainment products. This same media has also create sophisticated marketing and advertising models intended to shape what each of us sees as we look at the world through mediated glasses, so that our gaze, our wants, our actions are focused on those behaviours that are most easily capable of being translated into consumption.

What the commons makes possible is an environment in which individuals and groups can produce information and culture for their own sake. It allows for the development of a substantially more expansive role both for nonmarket production and for radically decentralized production. Already we are seeing nonprofit organizations using the World Wide Web to provide information or points of cultural exchange with much greater reach and efficacy than was ever before possible. No less importantly, the emergence of peer production of information and culture - phenomena epitomized by free software, but expanding to include news and commentary, as in slashdot, art, science, as well as directory and search facilities like the Open Directory Project ${ }^{1}$. Together these phenomena - the growth in the efficacy and reach of nonmarket actors and the emergence of radically decentralized information production - provide an enormously important counterpoint to the industrial information economy of the twentieth century.

But the democratic advantages, the individual freedom, and the growth through innovation that is made possible by the emergence of nonmarket and decentralized production will not emerge inexorably. The industrial giants that dominated information production and exchange in the twentieth century will not lightly relinquish their dominance. As we transition to a networked information economy, every point of control over

1. $<\mathrm{http}: / / \mathrm{dmoz}$. org/>. the production and flow of information and culture becomes a point of conflict between the old, industrial model of production and the new distributed models. At the physical layer, ownership over wires and wireless licenses that are necessary to communicate provides a point of leverage for control. At the logical layer, necessary standards, protocols, and software like operating systems - provide a point of control over the flow, and therefore the opportunities of production, of information and culture. At the content layer, intellectual property and business models that depend on tight control over existing information and culture - a central input into new creation threaten to provide their owners with the ability to control who gets to say what to whom with the core cultural signifiers of out time.

\section{A Core Common Infrastructure}

In order to capture the benefits of freedom and innovation that the networked information economy makes possible, we must build a core common infrastructure alongside the proprietary infrastructure. Such a common infrastructure will stretch from the very physical layer of the information environment to its logical and content layers. It must be extended so that any person has some cluster of resources of first and last resort that will enable that person to make and communicate information, knowledge, and culture to anyone else. Not all communications and information production facilities need to be open. But there must be some portion of each layer that anyone can use without asking permission from anyone else. This is necessary so that there is always some avenue open for any person or group to articulate, encode, and transmit whatever he, she, or they want to communicate - no matter how fringe or unmarketable it may be.

The primary strategies for building the core common infrastructure are:

- An open physical layer should be built through the introduction of open wireless networks, or a spectrum commons.

- An open logical layer should be facilitated through a systematic policy preference for open over close protocols and standards, and support for free software platforms that no person or firm can unilaterally control. More important are the reversal or refusal to adopt coercive measures that prefer proprietary to open systems. These include patents on software platforms, and the emerging cluster of paracopyright mechanisms like the United States' Digital Millennium Copyright $\mathrm{Act}^{2}$, intended to preserve the industrial business models of Hollywood and the recording industries by closing the logical layer of the Internet

- An open content layer. Not all content must be open, but intellectual property rights have gone wildly out of control in the past decade, expanding in scope and force like never before. There is a pressing need to roll back some of the rules that are intended to support the twentieth century business models. These laws were passed in response to heavy lobbying by incumbents, and ignored the enormous potential for nonmarket production and decentralized individual

2. <http://www.loc.gov/copyright/legislation/dmca.pdf>. 
production to become central, rather than peripheral, components of our information environment

- Reforming organizational and institutional structures that resist widely distributed production systems.

- The earliest large-scale successful model has been free software, with its informal social networks girded by the formal institutional framework of copyleft and open source licensing.

- In science, we are seeing the early emergence of efforts by scientists to release science from the old industrial publication model. The Public Library of Science $^{3}$ and the Budapest Open Access Initiative ${ }^{4}$ are the first primary efforts in this direction. They promise to provide a framework in which scientists - who already do the science, review the papers, and edit the journals more-or-less for free - can manage their own publication systems without relying on the large commercial publishers.

- In publication more generally, the emergence of the Creative Commons is an enormously important facilitating institutional framework.

- In informal personal communications, blogspace is emerging as an interesting social space for free, independent, and widely distributed information production.

3. <http://www.publiclibraryofscience.org/>.

4. <http://www.soros.org/openaccess/>.
- In each case, the particular characteristics of the type of information, the institutional barriers of incumbency, and the social patterns of use are somewhat different. In each case, the solutions may be somewhat different. But in all cases we are seeing the emergence of social and institutional structures that allow individuals and groups to produce information free of the constraints imposed by the need to sell information as goods in a property-based market.

We stand at a moment of great opportunity and of a challenge to our capacity to make policy that puts human beings at the centre of the networked information society. Digital networks offer us the opportunity to enhance our productivity and growth while simultaneously improving our democracy and increasing individual freedom. These benefits come at the expense, however, of incumbents who have adapted well to the industrial model of information production, and are finding it difficult to adapt to the networked information economy that would replace it. These incumbents are pushing and pulling law, technology, and markets to shape the coming century in the image of the one that passed. It would be tragic if they were to succeed.

Building a core common infrastructure is a necessary precondition to allow us to transition away from a society of passive consumers buying what a small number of commercial producers are selling. It will allows us to develop into society in which all can speak to all, and in which anyone can become an active participant in political, social, and cultural discourse. 